\title{
Disc and strut embolisation after minor strut fracture in a Björk-Shiley mitral valve prosthesis
}

\author{
Y KHALIL, B SETHIA, RO QUIN, WH BAIN \\ From the Department of Cardiac Surgery, Western Infirmary, Glasgow
}

We have reported previously the successful management of a patient who suffered embolisation of a Björk-Shiley mitral prosthetic valve disc after fracture of the minor strut.' On that occasion we suggested that retrieval of the embolised fragments might be safely undertaken at a second operation after stabilisation of patient's condition. We now report the successful management of a patient in whom synchronous retrieval of the minor strut and valve disc at the time of mitral valve replacement was required after embolisation of the strut to the right common carotid artery.

\section{Case report}

A 44 year old man was admitted as an emergency complaining of acute dyspnoea. He had undergone mitral valvotomy 15 years previously and mitral valve replacement in 1982 with a $31 \mathrm{~mm}$ Björk-Shiley concavoconvex prosthesis. His subsequent postoperative course had been uneventful and he had been entirely well until two hours before admission.

On examination he was orthopnoeic with peripheral cyanosis and evidence of acute pulmonary oedema. His blood pressure was $80 / 50 \mathrm{~mm} \mathrm{Hg}$ and his heart rate was 130 beats per minute in sinus rhythm. The heart sounds were faint and prosthetic valve sounds were absent. A pansystolic murmur was heard at the apex and over the scapula. Emergency radiological screening identified the disc of the valve in the abdominal aorta and the fractured minor strut at the bifurcation of the right common carotid artery.

He was taken to the operating theatre and placed on cardiopulmonary bypass. The left atrium was opened and the preoperative diagnosis was confirmed. Mitral valve replacement was undertaken uneventfully with a $31 \mathrm{~mm}$ Björk-Shiley monostrut prosthesis. At the end of the procedure the patient's condition was stable and, in view of the potential hazard of leaving the minor strut at the right common carotid bifurcation, it was decided to remove both the minor strut and the disc from the abdominal aorta.

The aorta was therefore exposed through a tranverse abdominal incision and the disc, which had been lying just below the level of the renal arteries, was removed unevent-

\section{Accepted 25 October 1984}

Address for reprint requests: Professor WH Bain, Department of Cardiac Surgery, Western Infirmary, Glasgow, G11 6NT.

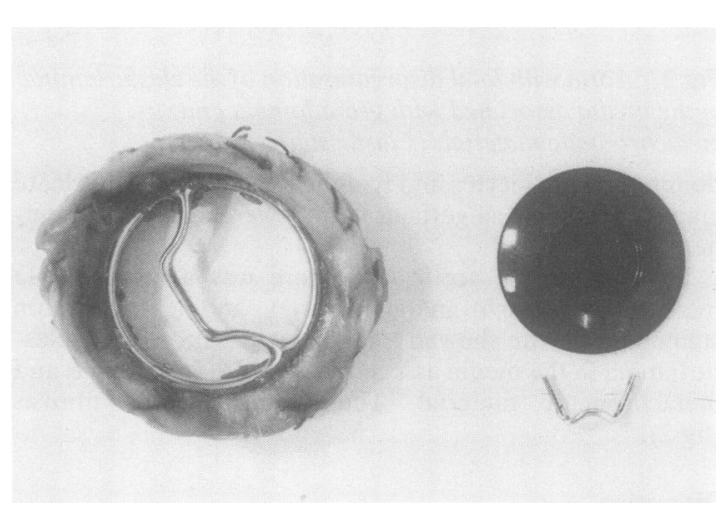

Excised mitral valve prosthesis with the fractured minor strut and valve disc.

fully. The common carotid artery was then exposed and the strut palpated easily at the bifurcation of the carotid. The strut was retrieved through a small transverse incision with a carotid artery occlusion time of two minutes (fig).

The postoperative course was uneventful. The patient was ambulant on his second day and was discharged eight days after surgery. At early follow up he remains well and his valve prosthesis is functioning normally.

\section{Discussion}

Several reports attest to the importance of emergency valve rereplacement embolisation of a prosthetic disc or $\mathrm{N}$ ball occluder. ${ }^{1-4}$ We previously reported disc embolisation after minor strut fracture in a Björk-Shiley concavoconvex mitral valve prosthesis ${ }^{i}$; but in that case we recommended $\omega$ later removal of the embolised disc, believing that the risk $\underset{\gamma}{\sigma}$ of concurrent abdominal and cardiac surgery might result 0 in an increased postoperative morbidity. In this instance, $\frac{\Gamma}{\Phi}$ however, the risk of postoperative cerebral complications $\stackrel{\mathscr{S}}{\longrightarrow}$ appeared to be increased by the presence of the strut at the right common carotid bifurcation and it seemed reasonable to remove this before it could migrate to a different site. $\overrightarrow{\mathbb{D}}$ Our experience emphasises the importance of immediate $\stackrel{?}{+}$ reoperation after fracture of a Björk-Shiley valve minor $\stackrel{\mathbb{Q}}{\varrho}$ strut and demonstrates the feasibility of concurrent surgery 
to recover the embolised fragments without an increase in postoperative morbidity.

\section{References}

1 Sethia B, Quin RO, Bain WH. Disc embolisation after minor strut fracture in a Björk-Shiley mitral valve prosthesis. Thorax 1983;38:390-1.

2 Ibarra F, Gutierrez A, Martinez F, Carreras L, Lopez C and
Alonso-Lei F. Fracture of the outlet strut of a Björk-Shiley mitral prosthesis: emergency operation with survival. J Thorac Cardiovasc Surg 1984;87:315-8.

3 Hughes DA, Leatherman LL, Norman JC, Cooley DA. Late embolisation of prosthetic mitral valve occluder with survival following re-operation. Ann Thorac Surg 1975; 19:212-5.

4 Ansbro J, Clark R, Gerbode F. Successful surgical correction of an embolised prosthetic valve poppet. $J$ Thorac Cardiovasc Surg 1976;72:130-2.

\section{Book notices}

Sleep and Breathing. Nicholas Saunders, Colin E Sullivan (eds). (Pp 640; SFr 213.) Marcel Dekker Inc. 1984.

This is the 21st volume of the series "Lung Biology in Health and Disease." The international and multiple author nature of the book makes for some uneveness of style but each chapter is carefully researched and often provocatively speculative, and provides a rich pool of references. The first seven chapters are mainly physiological, beginning with the neurobiology of sleep and covering central neural interactions, arousal responses, upper airway function, and neurochemical influences, and finishing with two chapters on the effect of sleep on the cardiovascular system and on the respiratory muscles. Two chapters on the clinical significance of snoring and the pathophysiology of sleep apnoea lead to the last six chapters, which are clinically based. A review of sleep apnoea syndromes is followed by an interesting psychiatric perspective by Bruce Singh. The regulation of breathing during the perinatal period and the sudden infant death syndrome are well covered, as is gas exchange during sleep in chronic airflow obstruction. The final chapter brings together information about sleep and breathing in many lung conditions, including asthma and cystic fibrosis. Research workers and clinicians will find much of interest in this volume, not least the rich source of references, but it is not easy bedtime reading. $-\mathrm{KP}$
Clinics in Immunology and Allergy. J Pepys (guest editor). (Pp 196; £12.50.) WB Saunders Company. 1984.

Occupational asthma and extrinsic allergic alveolitis are diseases where there has been a great deal of progress over the last few years, both in terms of identifying relationships between exposure and sensitisation in industrial popalations and in terms of elucidating basic mechanisms. This book contains by far the best collection of papers on this important subject so far available. There is an introduction on the clinical and epidemiological methods used for the investigation of occupational asthma, which sets the basis for the remaining chapters reviewing the literature on the commoner causes of occupational asthma. There are particularly good chapters reviewing the laboratory immunological methods for antigen characterisation and antibody detection, particularly with laboratory animals, platinum salts, isocyanates, and trimellitic anhydride. There are authoritative chapters on occupational asthma due to isocyanates, epoxyresin curing agents, and colophony. The complicated literature on wood dusts, cotton, and grain is also well reviewed. The book finishes with a review of occupational extrinsic allergic alveolitis. The whole book is written by authors with considerable personal experience and authority in the subject and should form a useful reference text for this difficult field for some time to come.-PSB 